\title{
Making women monk in Thai Society and Gender Inequality in Early Buddhism
}

\author{
Dr Rita Kumari ${ }^{1}$ \\ ${ }^{1}$ (Department of Political Science,VinobaBhaveUniversity,Hazaribag(Jharkhand),India,825301
}

\begin{abstract}
In Thai society today, primarily the women run daily affairs, where females outnumber males. Over the last few decades to where women fulfill many of the major roles in society. In Thailand women are deserving the majority of university enrollments, the breadwinners in many families are women, many corporate executives and civil servants are women.The majority of new entrepreneurial start-ups are undertaken by women.Many women such as SikharaMaha-Devi, Nang Nopamas, Queen Suriyothai, Nang Suang and Queen Sirikit have given the important contributions made in Thai society today and helped to shape Thai culture, customs, and traditions either as regents themselves or as direct advisors to their kings.This paper shows that how the Thai constitution is silent on women becoming monk;:although women were given the right to vote back in 1932, they were never given the right to be ordained as a monk, which may be treated as gender discrimination ,rather say gender inequality.The Bhikkhuni struggle highlights gender discrimination in Thailand. As a 'farang' or 'westerner', it would be too tempting to interpret what DhammakamalaBhikkhuni once told during interview as an expression of feminism.
\end{abstract}

Keywords: Bhikkhuni, breadwinners, enrollments, entrepreneurial, gender discrimination

\section{Introduction}

After taking a close look at Thai society today, it could be argued that it is primarily the women who run daily affairs. In a country where females outnumber males, the gender dynamics of the nation have dramatically shifted over the last few decades to where women fulfill many of the major roles in society. The majority of university enrollments are women, the breadwinners in many families are women, many corporate executives and civil servants are women, the majority of new entrepreneurial start-ups are undertaken by women, and even many farmers are women. Dr. SiriwanRatanakarn from Bangkok University in a paper on the women's role in Thai society discusses the important contributions made by such women as Nang Suang, SikharaMaha-Devi, Nang Nopamas, Queen Suriyothai, Queen Saovabhaphongsri, and Queen Sirikit. She states that these women have helped to shape Thai culture, customs, and traditions either as regents themselves or as direct advisors to their kings. She also points out how, during the Sukhothai period, women were portrayed as equal partners to men.

However, even with general acceptance about the emerging importance of the matriarchal role of women in society today, there is still one last bastion forbidden to women. This is the domain of the Buddhist monkhood, something that has been strictly taboo for women in Thailand for the last seven centuries. ${ }^{1}$

\section{Unequal Rules for Nuns}

TheVinaya-pitaka section of the Tripitaka (Pali Canon) records the original rules of discipline for monks and nuns. A bhikkuni (nun) has rules in addition to those given to a bhikku (monk). These include subordination to monks; the most senior nuns are to be considered "junior" to a monk of one day.Some scholars point to discrepancies between the PaliBhikkuniVinaya (the section of the Pali Canon dealing with the rules for nuns) and other versions of the texts, and suggest the more odious rules were added after the Buddha's death. Wherever they came from, over the centuries the rules were used in many parts of Asia to discourage women from being ordained. When the orders of nuns died out in India and Sri Lanka centuries ago, conservatives used the rules that called for monks and nuns to be present at nuns' ordination to prevent the institution of new orders. Only recently has the ordination problem been solved by allowing properly ordained nuns from other parts of Asia to travel to ordination ceremonies. However, the establishment of nuns' orders in Tibet, where there had been no nuns before, for some time met with resistance. Even today, in some parts of Asia nuns receive less education and financial support than monks. ${ }^{2}$

\section{Right of women in Thai Constitution}

Although women were given the right to vote back in 1932, they were never given the right to be ordained as a monk. There is nothing in the Thai constitution forbidding women becoming monks. However the 
Sanghacouncil which governs the monkhood continues to maintain that only men can enter the monkhood. This is based upon the Sangha Act 1928, which to all intents and purposes is still upheld as being valid.

The Theravada Bhikkhuni order was never "officially" established in Thailand, although it exists in both Myanmar and Sri Lanka. The absence of Bhikkhuni in Thailand over the last century has led to the perception among many Thais that women are not meant to play a monastic role in life other than being a lay follower, or becoming a Mae $J i$, or nun. Although a Mae $J i$ is higher than a lay person, this place within the monastic hierarchy tends to be seen as subservient to monks. In addition, monks receive free public transport, reserved seats in public places, and government identity cards, which Mae $J i$, just aren't entitled to.

This restricts women in the monastic hierarchy to only participating in activities of obtaining merit through collective rituals, and undertaking the housekeeping activities within a temple. Basically they are there to serve the monks. ${ }^{1}$

\section{Perception about nuns within Thai society}

A common perception by many within Thai society about nuns, is that while they are robed in white, they are most probably present in the temple because they have no other place to go, suffer from a broken relationship, have a psychotic disorder, or have very little education.

Consequently robed nuns tend to be looked down upon, with the general belief in some quarters that women are of less value than their male counterparts in monastic life.

To some women, the role of Mae $\mathrm{J} i$ or nun makes them feel very restricted, preventing them from doing more. This is according to DhammakamalaBhikkhuni, the deputy abbess of the ThippayasathandhammaBhikkhuniArama Centre, in Kohyor, Songkhla.

To many women who became a Bhikkuni, the feeling of materialism, relationships, and career, began to lose the importance it once had for them. They develop a feeling of emptiness in life, which needs to be quenched through some form of change. However being only a Mae Ji or nun is not enough. They want to do more through the personal freedom a Bhikkhuni potentially has to contribute to the community and dhamma, in their own way, different from their male counterparts.

A small number of women who have become Mae ji, aspire for full ordination in Thailand, even though 'officially' they would become a social outcast, in risk of civil prosecution of impersonating a monk.

The pioneer who led the way for women to be ordained as monks was the professor, controversial author, and TV host ChatsumarnKabilsingh, now known as DhammanandaBhikkhuni. She is now the abbess of WatSonghammakalyani in NakkonPathom, just North of Bangkok. DhammanandaBhikkhuni slipped away to Sri Lanka back in 2001 to return an ordained monk, being a very controversial move at the time. Since her ordination, DhammanandaBhikkhuni has built up the monastery, established by her mother VoramaiKabilsingh who was ordained under the Mahayana tradition in Taiwan in 1971, where more than 100 Bhikkuni have passed through the gates and scattered around a number of provinces. There is also a substantial sramaneri or novice nuns who are training for public ordination at the monastery.

WatSonghammakalyan has differentiated itself from male dominated monasteries in Thailand, in that the Bhikkuni have developed a strong rapport with the communities around them, and an exemplary empathy and ability to address the needs of the local residents. The bhikkuni directly engage the community, not just helping in their spiritual needs, but rendering assistance in many other ways, especially to the needy, sick, and infirmed. The Bhikkhuni were there giving assistance when floods hit their community a couple of years ago. ${ }^{1}$

\section{Aspiration of women for monk ordination}

What appears to be one of the important aspirations for sramaneri women who want to be fully ordained as a monk, is to be ordained in Thailand in front of their peers, rather than run away to another country to be ordained, and then returning to proclaim themselves a Bhikkhuni. This is now possible where a member of the Sri Lanka Sangha travels to Thailand for the ordination and a number of Thai Bhikkhu or male monks are willing to make up the necessary quorum of five Bhikkhu being present at the ordination. They feel it is symbolically important that ordinations are carried out in Thailand.

\section{Gender Inequality in Early Buddhism ?}

The various cited and worrying instances of gender inequality in Buddhist scriptures include isolated passages that openly disparage women, special rules allegedly imposed by the Buddha that entail an unequal relationship between the nuns' and monks' orders, the alleged reluctance of the Buddha to create a Nuns' Sangha, the greater number of rules nuns must follow in contrast to monks, and the poor historical track record of almost every sect of Buddhism with regard to gender equality. I will discuss these points one by one.

6.1 Isolated statements attributed to the Buddha in the discourses that seem to disparage women:- Here is an example from the early discourses: 
"Venerable sir, what is the reason that women neither come to the limelight, nor doing an industry see its benefits?"

"Ananda, women are hateful, jealous, miserly and lack wisdom, as a result they neither come to the limelight, nor do an industry and see its benefits." - AN 4.80

In fact this exchange is tacked awkwardly onto the very end of a sutta which begins with the theme of "nonsensual thoughts, non-hateful thoughts, non-hurting thoughts and right view" and furthermore seems to bear suspiciously no relationship whatever to anything else in the sutta. Yet there it is. As mentioned, the ancient Suttas have a complex history with much editing and insertion often by lesser minds long forgotten. There can be little doubt that this is a piece that belongs to someone else's grim jigsaw puzzle. The Suttas must always be read for the system that shines forth, the consistent message. We have to conclude that such remarks, not common in the Suttas, was a later insertion by a benighted monk, perhaps some once jilted lover, and not the words of the Buddha.

Although the origin this kind of discrepancy often seems clear, I should caution against dismissing too readily a statement in the scriptures that seems initially inconsistent to the reader. For instance, many passages, discourage monks from contact with women, for instance, not to look at them, not to talk with them, not to touch them, not to enter into a secluded space with them. For those unfamiliar with the nature or functions of Buddhist monastic practice, this may initially suggest misogyny clear and simple. But in fact ascetic traditions such as Jainism and monastic Buddhism give careful attention to controlling the passions, in particular sexual passion. This has nothing to do with gender bias at all; the woman renunciate is equally expected to avoid contact with men in exactly equivalent ways.

Another is the Buddha's often referenced statement in MN115 that a woman cannot become a buddha. On the surface this seems to place a limit on a woman's spiritual attainment, but the context reveals that this does not contradict womens' equal potential for awakening at all. In Early Buddhism a buddha is not only an awakened one but also someone who has the particular and very rare historical role of restoring Buddhism in the world so that otherscan achieve awakening.i.e,,Buddha=Awakened One+Original Teacher and Arahant= Awakened One. Only once in many eons a buddha arises in the world, discovers the truth that no one can teach him, and then propagates that truth so that others can share that buddha's awakening, thereby getting the ball rolling again. There is no question in the early scriptures that women can be arahants, that is, can share the Buddha's awakening. The claim must therefore be that only a man can be an Original Teacher. The context provided in the relevant passage confirms this. This is also true of universal monarchs, and dieties who bear influence in the world.

It is impossible that a woman should be the Perfectly Awakened One. It is possible that a man should be the perfect rightfully Enlightened One. It is impossible that a woman should be the Universal Monarch ... the King of Gods ... Mara ... Brahma ...

Now, being an Original Teacher requires a number of personal qualities, including charisma, physical stature, skill in exposition, a nurturing attitude, aptitude for strategic planning, a low, booming and articulate voice, etc. These qualities are largely determined by society in which he lives, so that a patriarchal society, for instance, that diminishes feminine qualities would not produce feminine original teachers, universal monarchs or mara, any more than a society which values thick heads of hair will produce bald televangelists. ${ }^{3}$

6.2. The Garudhammas (Heavy Rules): The most cited evidence of gender bias in the early texts where reportedly imposed by the Buddha as he established the Nuns' Sangha. They are recorded in the Vinaya as follows:

1. A nun who has been ordained even for a hundred years must greet respectfully, rise up from her seat, salute with joined palms, do proper homage to a monk ordained but that day.

2. A nun must not spend the rains in a residence where there are no monks

3. Every half month a nun should desire two things from the Order of Monks: the asking as to the date of the uposatha day, and the coming for the exhortation.

4. After the rains a nun must 'invite' before both Orders in respect of three matters, namely what was seen, what was heard, what was suspected.

5. A nun, offending against an important rule, must undergo manatta discipline for half a month before both Orders.

6. When, as a probationer, she has trained in the six rules for two years, she should seek higher ordination from both Orders.

7. A Monk must not be abused or reviled in any way by a nun.

8. From today, admonition of monks by nuns is forbidden, admonition of nuns by monks is not forbidden------------I.B. Horner, Book of the Discipline, V.354-55. ${ }^{4}$

Let me provide some brief explanations that will dispel some, but indeed not all, of the shock the Westerner generally experiences on first encountering these rules. They actually have less bite than bark, which as we will see is probably their primary purpose. 
First, putting aside gender roles, although the form of respectful greeting (rule \#1) is quite foreign to Western culture it would have been familiar in the Buddha's world, and still in most of Asia today it is a part of common etiquette, found for instance in the way children greet parents, students greet teachers, junior monks greet senior monks and lay men and women greet both monks and nuns. Yet the specific rule cited here clearly imposes a gender-based distinction within the Sangha, even while there are, for instance, no similar caste-based distinctions at all.

Second, there is little here in the way of a power structure. While the nuns may ordain other nuns, a group of monks must concur (rule \#6). And should a nun be sanctioned for a serious disciplinary infraction a group of monks must agree with the terms of the sanctions (rule \#5), which are largely specified in the Vinaya in any case. That's it, and for most nuns this is a rare or even once-in-a-lifetime matter. Otherwise monks have no authority at all to tell nuns what to do. Should a nuns' community finds the local community of monks uncooperative or obstructive in some way, they are free to align themselves with a more agreeable community of monks. To the extent the Garudhamma are present in the Nuns' Patimokkha, their violation is atoned by simple acknowledgement. Although the power allocated to the monks is of very limited significance, the rules again clearly do express a gender bias, for monks do not seek approval from nuns for their ordinations, nor for the terms of sanctions against their misbehavior.

Third, these rules set up a partial dependency of the nuns' community on the monks' community with regard to teaching and training, particularly during the time of the three-month yearly Rains Retreat (rule \#2 and rule \#3). Whereas this can be viewed primarily as an obligation of the monks to the nuns, and any potential for abuse of this relationship is carefully circumscribed in the Pațin ways already described, there is an nonetheless an asymmetrical relationship that attributes greater competence in practice and understanding to the monks.

Fourth, critical feedback flows in only one direction, from monks to nuns. The "invitation" is an occasion at the end of the Rains Retreat in which each monk or nun invites the others to provide constructive criticism of one's actions. Criticism of monks by nuns is excluded on this occasion (rule \#4) and on any other occasion (rule \#8). The puzzling inclusion of rule \#7 is not as gender-biased as it seems since monks are already prohibited from abusing or reviling anybody in any way.

As in the case of isolated statements, there is strong evidence that these rules, or at least some of them, are not the words of the Buddha. Not the least of this evidence is that the origin story makes little chronological sense given other events reported in the Suttas. Ananda's intervention on behalf of the would-be nuns, for instance, seems to have happened when he would have still been a young boy. Nonetheless if the Garudhammas did not originate with the Buddha they must have originated with very influential early disciples of the Buddha, since they have a prominent place in each version of the Vinaya. I think we do well to uncover the foggy motivation behind the Garudhammas before we attribute a discrepant understanding to those otherwise worthy disciples. ${ }^{3}$

6.3 The Buddha's resistance to establishing the order of nuns.

As told in "The First Buddhist Women," the Buddha originally refused to ordain his aunt Mahapajapati's lobbying effort to form a Nuns' Sangha until Ananda interceded on her behalf and elicited the famous statement from the Buddha that that allowing women into the sangha would cause his teachings to survive only half as long -- 500 years instead of a $1,000 .{ }^{2}$ Buddha said to him, "Ananda, I will give my approval on the condition that they accept the eight Garudhammas.I have laid down these dhammas for a female Sangha because I know that at first it will be weak and it will need support. It can be likened to a family in which there are more women than men. In such a family a thief can rob from them easily." The Buddha admitted there was no reason a woman could not be enlightened. "Women, Ananda, having gone forth are able to realize the fruit of streamattainment or the fruit of once-returning or the fruit of non-returning or arahantship," he said. ${ }^{4}$

Even as when the disease known as red rust attacks a whole field of sugar-cane, that field of sugarcane will not last long, even so, in whatever dhamma and discipline women obtain the going forth . . that dhamma will not last long. Even as a man, looking forward, may build a dyke to a great reservoir so that the water may not over-flow, even so, were the Eight Garudhammas for the nuns laid down by me, looking forward, not to be transgressed during their lives."

Again, some scholarship has questioned the authenticity of this statement along with the entire origin story of the Garudhammas, but also again it came from somewhere, so let us consider what the concern is that is expressed here. This envisions the slow deterioration of the Buddhist movement. Although the condition for this deterioration is identified as allowing women to ordain into the Sangha, how or why the deterioration proceeds is left obscure. This is what we should take pains to discover. It is also unclear to me whether or not the last line says that through the Garudhammas the problem has been fixed, that is, that the envisioned early demise of the Buddhist movement will thereby be averted.

Although the similes here make use of some strong negative imagery for the deterioration of the Buddhist movement, I think it is very rash indeed to see blatant misogyny in this, as if it were saying that womenare like 
white bones or red rust. These are similes about the deterioration of the Buddhist movement, not directly about women.

In short, what this passage does say is that all things considered expanding the Sangha to include women will set off a gradual deterioration of the Dharma. Given that great cost, it is no wonder that the Buddha (or at least his early disciples) would be hesitant to take the risk to include women. His boldness in allowing the value he place in women's practice to override this grave concern is to be commended. What is still obscure is the basis of this concern, how and why the inclusion of women, in spite of the Buddha's best intentions, might initiate this process of deterioration, and how the Garudhamma might help to avert this. I will take up this can of worms below.

6.4 The greater number of monastic rules imposed on nuns: The Theravada Patimokkha, the master list of rules, enumerates 227 rules for monks and 311 for nuns, and other Vinaya traditions reveal similar proportions. This is often cited as evidence for gender bias, but in fact the reasons for the extra rules are complex and diverse and do not admit to such a simple conclusion.

The primary reason seems to be that the Nuns' Patimokkha was compiled at a later date than the Monks' Patimokkha. Each represents a kind of snapshot of a moving target, one earlier than the other. In fact the body of rules prescribed by the Buddha seems to have grown over a long period of time, some of these rules specific to monks and some to nuns, but the bulk of them the same or equivalent. Each Patimokka, because it is a kind of master list serving for memorization and group recitation, seems to have been closed to further additions at a certain time, first the Monks' Patimokkha then the newer nuns'. This gave us two snapshots, the second showing a bigger set than the first, so that many rules prescribed by the Buddha in fact for both monks and nuns are found in the Nuns' Patimokkha but not in the monks'.

The Nuns'Patimokkha additionally includes most of the Garudhamma rules and the Monks' Patimokkha does not. As noted in the section on Gender Equality, differing but complementary rules also protect the nuns from potential gender-associated vulnerabilities in their interactions with monks and laity. Also the origin stories of the rules reveal that a number of rules that apply only to nuns arose from complaints lodged by nuns against the misbehavior of nuns.

Finally the nuns also have more rules specifically regulating sexual conduct. A body of rules for each order not only enforces celibacy but also helps the monastic to avoid compromising situations and to maintain propriety in this critical aspect of monastic practice. However, the nuns' circumstances are stricter in this regard because the nuns are easily subject to male aggression and are able to become pregnant. Consider how well-intentioned modern parents generally subject their teenage daughters to more oversight than they do their sons. The Buddha seems to have shared this attitude.

6.5. Gender bias in later Buddhism: Virtually every sect of Buddhism seems to have developed a degree of gender bias beyond the best intentions of the Buddha, for instance the loss of the Nuns' Sangha in many traditions. Since my concern here is the role of women in early Buddhiam I do not need to say much about this. Presumably this has arisen largely through the attitudes and continual pressure of the embedding patriarchal cultures found throughout much of Asia, as undoubtedly other institutions — businesses, government, military and so on - have. The Buddha described his teaching as "against the stream," which means that there is a constant tension between the Dharma-Vinaya on the one hand and popular opinion and habit on the other. When the latter overwhelms the former the Sangha has failed to preserve the purity of the teachings. How could this happen?

Woefully it seems that as the early context in which the scriptures arose began to recede into ancient history, particularly quickly in lands outside of India itself, many passages were in fact reinterpreted to endorse various forms of gender discrimination. We have seen, for instance, that the statement that a woman cannot become a buddha was rather benign in its original context, with no substantial relevance for the spiritual expectations of women practitioners. However the meaning of "buddha" shifted in the later Mahayana tradition to become, rather than a rare historical role, an attainment higher than arhantship to which all Buddhists were encouraged to aspire. When the word "buddha" was reinterpreted in this way then the statement that a woman cannot become a buddha indeed limited a woman's spiritual expectations. This may be a basis of the common Mahayana view that women have an unequal capacity for progress on the path, or that in order to attain awakening they must first be reborn as men. Likewise the Garudhamma rules, whose motivation in Buddha's India we have yet to fully examine, could then easily be read as confirmation of women's inferior capacities, once these motivations are obscured, particularly because they are formulated in such symbolic (bark) rather than practical (bite) terms. 6.6. The fog clears: In summary the fog that threatened to obscure the image of the Buddha and early Buddhism that had clearly shined through by the end of the section on Gender Equality has lifted. Taken on a case-by-case basis each piece that seemed to challenge our puzzlers' skill has snapped into place ... except around two remaining issues: the purpose of the Garudhamma rules and the Buddha's reported hesitation in establishing the Nuns' Sangha. These require closer examination. 


\section{Conclusion}

For promoting the cause of women, the Buddha can be considered as the first emancipator of women and promoter of women and promoter of a democratic way of life. It is to the eternal credit of the Buddha-Dhamma that women were not despised and looked down but were given equal status with men in their spiritual endeavor on the way to gain wisdom and the complete deliverance - Nibbana ${ }^{5}$

The Buddha clothed the Sangha in respectability according to the standards of the society in which he lived. This strategy gained room for the Sangha to become the ideal society within with minimal interference from the faulty society without. In the ideal society the same opportunity for practice is secured for women as for men. Unfortunately in a modern society the clothes have a poor fit, they sometimes offend.The monastic rules have historically always bent to changing climate, geography, technology and society. The Sangha would not have survived if this were not the case. At this point in history it is imperative that any semblance of gender inequality, symbolic or otherwise, be removed in a Buddhism that retains the heart of the Buddha's original intention and can thrive in a modern culture. I have said nothing about the politics of how to get there from here, about untangling the force of ancient traditions, of maintaining harmony and respect among conservative and liberal elements in these traditions with regard to women's equality, about how to introduce or reintroduce full ordination for women in those traditions that lack it. It may take patience but the necessary adaptation will certainly happen. ${ }^{3}$

The ordination of Bhikkhuni has not been a major issue of discussion for over a decade. However with the regular ordination of women occurring in the near future, it is likely that the issue will be debated once again. The biggest barrier to the ordination of women may lie in that it is a total affront to 'what is', and consequently seen as a threat to the establishment, which has existed under the same structure for over a century. Consequently conservatism rules to maintain the status quo rather than consider 'what could be'.

Institutionally, the only consolidation is that the current small number of Bhikkhuni are generally left alone and have not been prosecuted.However Buddhism in Thailand according to some, needs some revitalization and effort made to regain the confidence of the people after some of the scandals of late. The whole question of getting the dhamma across to a rapidly changing society needs a rethink. This requires some reconsideration about the entry of women to the Sangha or monkhood. ${ }^{1}$

If Thailand is going to retain its leadership in the development and dissemination of dhamma, then it needs to appeal to all segments of the populace. These are challenges facing the Sangha Council which must address the institution of Bhikkhuni to maintain its relevance to society and prevent itself from becoming an institutional relic.

Unrecognized and unacknowledged women monks are at the forefront in dealing with Thailand's social problems, if even on the small scale, while many of their male counterparts have withdrawn themselves from society to stay within the temples of Thailand.

Ironically this issue appears to be as hard to solve as the ongoing political turmoil playing out on the streets in Bangkok. However the Bhikkhuni have a secret weapon with their charm and devotion that is winning the hearts and minds of many who come into contact with them.

The emergence of the Bhikkhuni phenomenon is a strong wind of change blowing across both the social and spiritual aspects of Thai society. Society may not be able to resist this idea, as its time may have come

References

[1] Murray Hunter, Making monks of women, On Line Opinion e-Journal, posted December,27, 2013

[2] Barbara O'Brien, Buddhism and Sexism,can There Be Buddhist Gender Equality? , Free Buddhist Newsletter,about.com

[3] Buddhism,snapshot ,12,March,2013

[4] bhikkhucintita the dinsmor,Buddhistwritings, What Did Buddha Think of Women,Through the Looking GlassDhammakaro,Female Monks in Buddhism,Buddhapadipa Temple

[5] VenDrK.SriDhammananda,Status of Women in Buddhism,Washington Buddhist Vihar,newsletter,2003-winter 